\title{
A SURVEY ON VARIOUS COMMUNICATION APPLICATIONS
}

\author{
BABITA BHAGAT ${ }^{1}$, SRIJITA BHATTACHARJEE ${ }^{2} \&$ SUSHILA RATRE $^{3}$ \\ ${ }^{1,2}$ Assistant Professor, PHCET, Rasayani, Maharashtra, India \\ ${ }^{3}$ Assistant Professor, AMITY University, Mumbai, Maharashtra, India
}

\begin{abstract}
Today wide scopes of chances are given by web, and the mix of web alongside PC has gotten some radical changes different everyday exercises, particularly in the field of instruction. This blend of web and PC is reshaping the more seasoned learning framework into a new learning framework known as "E-learning". This task presents the possibility of E-discovering that utilizes the systems administration advancements that help to give another instructing learning experience. It means improving the showing experience by empowering the sharing of an instructor's work area among understudies and furthermore moving voice of educator over associated understudy's PC. This will help the person to show one specific idea to various understudies who are sitting in various areas. This paper gives an overview of the five correspondence applications like zoom, group watcher, Cisco WebEx, Google home base meet and Skype by thinking about numerous parameters.
\end{abstract}

KEYWORDS: Communication Application, Comparison, Security, Accessibility

Received: Jun 01, 2020; Accepted: Jun 20, 2020; Published: Jun 30, 2020; Paper Id.: IJMPERDJUN2020139

\section{INTRODUCTION}

Regardless of whether you're in a gathering or doing client service, screen sharing is probably the most ideal approaches to represent your point without disappointing anybody in the call. That is in the event that you can get an application that lets you share your screen without an issue. We've all been there previously - you've appeared ahead of schedule to a gathering just to have your innovation bite the dust on you. Possibly the call quality was so awful you were unable to hear each other talk or maybe the other individual had to download another application before having the option to see your screen. Regardless of your difficulties, this rundown will clear up which screen sharing applications are the best for you to utilize, why, and why different alternatives aren't adequate.

\section{RELATED WORK}

In this paper Trisha Dowerah Baruah found Collaboration through online mode ends up being basic if it is supported by electronic long range interpersonal communication propels. For instance, understudies can cooperate on bunch adventures. Understudies in a comparable report get-together can co-draft files, spreadsheets, presentation slides, and more with Google Docs. Representatives are getting the cash for on the creating commonness of blogging and scaled downscale blogging by using on the web diaries as extra teaching/learning resources. Online life gives clear, conservative ways to deal with sort out people, plan social events, spread information, and measure end. As more structures ascend, there will be an increasingly significant breaking point regarding get-togethers to mastermind and check out the total movement, an indication of basic culture. Online life can be ground-breaking for building social position; individuals or affiliations can set up themselves as pros in their fields, and a while later 
they can begin to affect these fields. As needs are, one of the essential thoughts in web-based life is that, with electronic life, one can't control one's message absolutely, yet one can add to talks. Electronic long range interpersonal communication progressions are prepared for reaching swarms wherever all through the world.

In this paper Michiko Kobayashi discovered online courses, teachers and understudies must depend on innovation to speak with one another. Picking fitting innovation that meets the objective of the movement is significant. The current investigation uncovered that Google Hangouts may not be a simple program to learn, however, it can possibly be a helpful instructional and collective device. synchronous and offbeat online instrument impacts affect understudy learning. On certain events, no concurrent correspondence configurations may preferably meet the instructional goals over constant communications would. Google Hangouts is a generally new program, and there isn't yet much writing that investigates its application in instructional settings. In this investigation, just a few understudies reacted to the review in the wake of partaking in the Google Hangouts movement. The specialist prescribes further examination concerning Google Hangouts in a diverse setting. Understudies' discernments about Google Hangouts may differ, contingent upon their nations of the starting point. Looking at changed videoconference programs in one-on-one and gathering settings will assist us with recognizing innovation proper for arranged course exercises.

In this paper Lo Iacono, Valeria, Symonds, Paul, and Brown, David H.K they have talked about favourable circumstances just as impediments of Skype for subjective meetings. Be that as it may, they additionally featured how the confinements can be survived or, now and again, make new chances. In general, they would not contend that interviews by means of VoIP innovations, for example, Skype ought to totally supplant face to face meets. Rather, VoIP techniques are best seen as a complementary information assortment apparatus for subjective specialists, which functions admirably close by other information assortment strategies as a component of a more extensive research plan and system. Found in these terms along these lines, we don't share the benevolent counsel of King and Horrocks (2010: 84) that 'subjective analysts ought to be mindful about the utilization of remote video for interviews'. Lords and Horrocks inform alert on the grounds that concerning specialized glitches in sound and video transmission. Be that as it may, since 2010, the nature of VoIP advances has tremendously improved. Despite the fact that not appropriate for all occurrences of subjective talking, where meeting subjects from a different land and socio-social range is favourable to the investigation, we would contend that VoIP video inquires about techniques may be grasped with some certainty, instead of warily considered.

In this paper, Mandy M. Archibald, Rachel C. Ambagtsheer, Mavourneen G. Casey, Michael Lawless, explore on applied WebEx Conferencing to DLIT. The test bed has completely structured and actualized the entire framework. The clients are gotten to through the site page by introducing the Plug-In on an internet browser as it were. In the visual homeroom, clients can trade information records in the group, share introductions, share work area, remote work area, share documents, whiteboard features, and private visit gatherings. In addition, WebEx is a protected internet conferencing and is additionally ready to record the gathering for sharing on the site later.

\section{ABOUT COMMUNICATION APPLICATIONS}

In this paper we are comparing five communication applications, so let us know some features of the application:

\section{Skype}

Skype is for interfacing with the individuals that difficulty maximum in your existence and work. It's worked for each oneon-one and gathering discussion and works any vicinity you are - via versatile, PC, Xbox, and Alexa. Skype informing and 
HD voice and video calls will help you with sharing encounters and entire matters others. With Skype, you may have gatherings and make exquisite things with your workgroup, share a tale or commend a birthday with loved ones, and advantage proficiency with any other aptitude or enjoyment pastime with an instructor. It's allowed to utilize Skype to send messages and feature sound and video calls with gatherings of up to 50 individuals. On the off chance that you pay a bit, you may accomplish more things, in greater ways, with greater people - like name phones or SMS messages. You can pay greater handiest as costs get up or buy a membership, something works for you. Attempt Skype out today and start which include your companions, family, and associates. They might not be elusive; a big wide variety of people are as of now making use of Skype to do a wide range of factors together.

\section{Features of Skype}

\section{- Compactness}

Being founded on the cloud innovation, Skype for Business lets you associate with your working environment from anyplace, whenever and through any gadget. In this manner, your office goes with you. You can dial in from anyplace through a web association and partake in video, sound and online conferencing.

\section{- Upgraded Accessibility}

With Skype for Business, you have simple availability to gatherings and schedules. This encourages you to stay refreshed with the most recent undertakings, timetable and track your gatherings in a hurry and act rapidly.

\section{- Online Meetings}

Direct gatherings like you're across the board room when actually you are most certainly not. It empowers you to participate in sound, video, and web conferencing in a hurry. You can plan gatherings ahead of time. Skype for Business can be effectively coordinated with Outlook, empowering you to plan any gathering through Outlook inside a couple of snaps.

\section{- Record Skype Calls Mac, Work Area and Cell Phones}

Skype for Business permits you to record significant gatherings with your partners. The call recording usefulness is totally cloud put together and is accessible with respect to the most recent adaptation of Skype on a large portion of the stages.

You can record Skype calls for Mac also utilizing different outsider programming accessible in the market.

When you start recording, everybody in the call is told. After the call, the chronicle can be spared and shared for the following 30 days.

\section{- Telephone Support}

Move away from the restrictive phone frameworks to an increasingly effective method for making calls utilizing Skype for Business. You can just make, get, and move calls utilizing telephone, Mac, PC and versatile.

\section{- Control Dashboard for Members}

\section{TeamViewer}

TeamViewer is a short and secure across the board answer for having access to PCs and structures remotely. With a scope of amazing remote get entry to includes that easily deal with remote manipulate, gatherings and keeping up a cloud- 
based help work area, there may be a big organization of assets telling you exactly the satisfactory way to saddle thewhole intensity ofTeamViewer.Withsupportive client manuals, preliminary step information and standard howto publications accessible, you'll adapt exactly how to utilize TeamViewer without limit. In the case of making use of the across the board arrangement as an IT workplace or an oversaw specialist organization, instinctive capacities, for example, Wake-on-LAN, unattended get entry to and ticket appointing are all available to you. The underlying TeamViewer association could not be simpler: simply introduce the product, show whether you want to make use of it for enterprise or non-public use, make a name and mystery key in your PC, and make notice of it for future reference. When the establishment method is finished, you'll at that point be taken to the precept TeamViewer interface, which is split into two tabs: remote control and meeting. From here, you may discover the distinctive highlights plot beneath.

\section{TeamViewer Features}

TeamViewer can be utilized with Windows, Mac, and Linux and furthermore has an edition that is probably utilized on iPhones. There is a portable form that can be put on a circle or USB stick, which makes this an powerful opportunity for those that move. TeamViewer's adaptability makes it beneficial as a rule.

- Training recordings, introductions, and exhibitions can certainly be shared by utilizing TeamViewer. It likewise incorporates a status display with the aim that colleagues can rapidly find out each other and convey.

- TeamViewer would not require each system to have the product introduced. This is particularly useful in client care circumstances. The consumer can run the program without established order, which lets in the expert far off access so as to provide help. The specialist's workstation calls for the establishment and a permit.

\section{Zoom}

Zoom is the pioneer in present-day challenge video correspondences, with a simple, reliable cloud level for video and sound conferencing, coordinated effort, talk, and online publications across cellular phones, work areas, phones, and room frameworks. Zoom Rooms is the first programming primarily based amassing room association utilized the world over inboard, meeting, cluster, and getting ready rooms, simply as official places of work and take a look at halls. Established in 2011, Zoom enables organizations and associations to unite their corporations in a frictionless domain to finish more. Zoom is traded on an open market agency on Nasdaq (ticker: ZM) and centered in San Jose, California.

\section{Zoom Features}

- $\quad$ PRODUCTS. Gatherings and Chat. HD video, sound, coordinated effort and visit. Rooms and Workspaces. Catalyst your meeting rooms with video. Video Webinars. Full-highlighted, simple to-utilize, connecting with online classes.

- INDUSTRIES. Instruction. Extend conventional study halls in the cloud. Fund. Improve client encounters and interchanges. Government.

\section{CISCO WebEx}

The Cisco Webex Video Platform is incorporated with Meetings. Video conferencing is conveyed with a product asan administration (SaaS) version through the Cisco Webex Cloud with sound, video, and internet conferencing. It bolsters 
booked, Meets Now, and character Meetings video conferencing meetings. Cisco Webex Video Platform might be empowered through the Cisco Webex Cloud. Clients can be part of from numerous forms of gadgets, consisting of principles-based SIP and H.323 endpoints, and Webex customers. It offers stable business-to-business (B2B) and business-to-client (B2C) joint effort in a 'one collecting' experience. The 'one amassing' enjoy empowers a predictable sound, video, and substance sharing revel in for all customers who be part of. This offer offers all the benefits of a Cisco Webex empowered Telepresence arrangement, however, it stretches out adaptability by way of empowering clients to consume the management from the Cisco Webex Cloud. Cisco Webex Video Platform empowers gatherings to be made as deliberate or Meet Now gatherings, or held in close to domestic collecting rooms.

\section{Cisco Webex Features}

- One Meeting - mixed video and web conferencing conveying a five-star revel in all from the Webex Cloud

- Join From Anywhere - from the pocket to the meeting room with true level autonomy including SIP and H.323

- Superior Scale - as much as 200 video endpoints and 500 movies empowered Webex customers in a solitary gathering, which can include becoming a member of from Webex Teams/Jabber, and restricted depending on the member top foryour specific record/membership.

- Industry Leading Proven Technology - Webex Meetings and Cisco Tele Presence Video Conferencing

- Scheduled and constantly on near to home Cisco Webex Meetings video conferencing alternatives

- Two-manner video supplying to as much as 720p screen desires among the Webex software and Tele presence gadgets

- Integrated sound an creation sharing - such as application and work location content material sharing potential for all clients ingathering

- Integrated software for Webex members, together with Telepresence device display names

- Network-based totally account (NBR) of gatherings which includes content offer, visit, and surveying

- Integrated assembly making plans with the Cisco Webex and Tele Presence Integration to Outlook or the Webex site

- Secure call manipulate and network empowered by using media encryption gave by way of Cisco Expressway-E or Cisco Expressway

- UnifiedCM-pushed andCiscoExpressway-pushed call manipulate sendingchoices

- Interoperability with outsider Telepresence gadgets

\section{Google Hangout Meet}

Google Hangouts is an American correspondence programming item created by Google. Initially an element of Google+, Hangouts turned into an independent item in 2013, when Google additionally started incorporating highlights from Google+ Messenger and Google Talk into Hangouts. In 2017, Google started forming Hangouts into an item focused on big business correspondence. Home bases is presently part of the G Suite line of items and comprises of two essential 
items: Google Meet and Google Chat. Google has additionally started incorporating highlights of Google Voice, its IP communication item, into Hangouts, expressing that Hangouts is intended to be "the future" of Voice. Google will close down the great G Suite rendition of Hangouts in June 2020 (being supplanted by Meet and Chat), however will keep on supporting the shopper form of exemplary Hangouts.

\section{Google Hangout Meet Features}

- Integration with all other G Suite items: Launch into video calls or content talks legitimately from messages or schedule warnings.

- Instant gatherings with outer members: Share a solitary connection for any gathering with up to 100 members for the essential arrangement, 150 for the field-tested strategy, and 250 for the venture plan.

- Integration with other video conferencing administrations utilizing the Pexip module: Integrate with other outsider video conferencing programming, similar to Cisco's Webex and Citrix's GoToMeeting, utilizing the Pexip module. (The Pexip module is a different outsider application and should be bought independently for use with Google Hangouts Meet.)

- Screen sharing and online introductions: Share screens and communicate introductions online to every single other client signed into the introduction. Virtual gathering rooms and study halls can even be held with clients who are signed in by means of a PC program or outsider web conferencing application.

- Recording gatherings: Record gatherings and spare them on the Google Drive distributed storage stage. Google Drive furnishes every client with $30 \mathrm{~GB}$ of capacity for an essential record and boundless stockpiling for business and undertaking accounts.

- U.S. also, worldwide dial-in telephone numbers: Dial into a gathering utilizing the U.S. what's more, International dial-in numbers when unfit to download the portable application or access to a PC.

- Livestreaming: Livestream gatherings or communicates by imparting connects to up to 100,000 individuals from the association. This component is accessible solely to the G Suite Enterprise and G Suite Enterprise for Educators supporters.

\section{COMPARATIVE STUDY}

In this paper comparative summary is shown by table and graph for the survey conducted by considering five communication application and based on 10 different parameters, I tried to find the most popular among the academician $n$ people working in industry. The most popular among the people is zoom for video conferencing meeting, more user friendly, screen sharing, session scheduling, freely available, recording facility, and feature rich in mobile apps, but when it comes for security the more votes are given to Google hangout, dynamic voice detection \& large rooms and webinar is more popular in CISCO WebEx. 
Table 1: Showing Questions and Percentage Allotment to the Different Application

\begin{tabular}{|l|c|c|c|c|c|}
\hline \multicolumn{1}{|c|}{ Questions } & Skype & Zoom & $\begin{array}{c}\text { TeamViewe } \\
\text { r }\end{array}$ & $\begin{array}{c}\text { CISCO } \\
\text { WebEx }\end{array}$ & $\begin{array}{c}\text { Google } \\
\text { Hangout }\end{array}$ \\
\hline $\begin{array}{l}\text { Which application do you recommend for } \\
\text { video conferencing/online meeting? }\end{array}$ & $39 \%$ & $64 \%$ & $11 \%$ & $32 \%$ & $46 \%$ \\
\hline Which application is more user friendly? & $25 \%$ & $64 \%$ & $7 \%$ & $32 \%$ & $39 \%$ \\
\hline Which application is more secure? & $14 \%$ & $46 \%$ & $4 \%$ & $29 \%$ & $36 \%$ \\
\hline $\begin{array}{l}\text { Which application has feature of screen } \\
\text { and application sharing? }\end{array}$ & $32 \%$ & $64 \%$ & $14 \%$ & $36 \%$ & $43 \%$ \\
\hline $\begin{array}{l}\text { Which application has the feature of } \\
\text { session scheduling facility? }\end{array}$ & $18 \%$ & $57 \%$ & $14 \%$ & $39 \%$ & $61 \%$ \\
\hline Which application is freely available? & $36 \%$ & $77 \%$ & $25 \%$ & $25 \%$ & $21 \%$ \\
\hline $\begin{array}{l}\text { Which application has session recording } \\
\text { facility? }\end{array}$ & $25 \%$ & $79 \%$ & $11 \%$ & $36 \%$ & $54 \%$ \\
\hline $\begin{array}{l}\text { Which application is used by feature-rich } \\
\text { mobile apps (iOS and Android)? }\end{array}$ & $43 \%$ & $79 \%$ & $14 \%$ & $36 \%$ & $32 \%$ \\
\hline $\begin{array}{l}\text { Which application has the feature of } \\
\text { dynamic voice detection? }\end{array}$ & $18 \%$ & $43 \%$ & $11 \%$ & $46 \%$ & $36 \%$ \\
\hline $\begin{array}{l}\text { Which application has the feature of large } \\
\text { room and webinars? }\end{array}$ & $29 \%$ & $46 \%$ & $0 \%$ & $50 \%$ & 5 \\
\hline
\end{tabular}

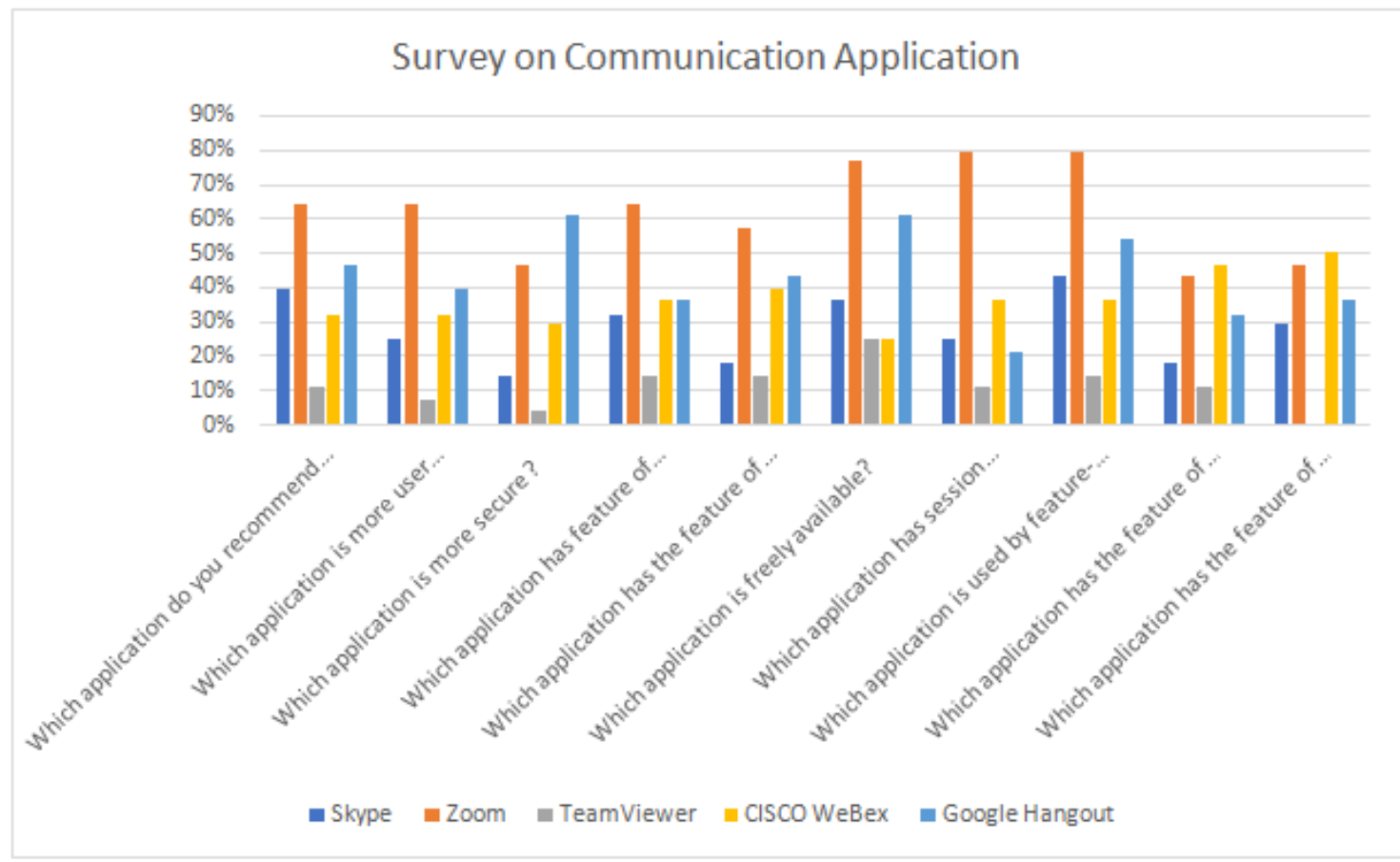

Graph 1: Representing Comparison among Different Communication Application.

\section{CONCLUSIONS}

Now days for online communication in this paramedic situation everyone wants to get connected by any means to get the work done let it be academician or industry people. In this paper comparison is shown by taking survey from many to show which application is better in security or different features. By considering the survey I conclude that zoom is the most 
popular among the users but in security aspect most popular is Google hangout. CISCO WebEx is also famous for its dynamic voice recording \& large webinars.

\section{REFERENCES}

1. Trisha Dowerah Baruah, Effectiveness of Social Media as a tool of communication and its potential for technology enabled connections: A micro-level study at International Journal of Scientific and Research Publications, Volume 2, Issue 5, May 20121 ISSN 2250-3153.

2. Michiko Kobayashi, Students' Evaluation of Google Hangouts through a Cross-Cultural Group Discussion Activity at Turkish Online Journal of Distance Education-Tojde April 2015 ISSN 1302-6488 Volume: 16 Number: 2 Article 3.

3. Lo Iacono, Valeria, Symonds, Paul and Brown, David H.K. (2016). 'Skype as a Tool for Qualitative Research Interviews'. Sociological Research Online 21(2)12

4. Jirayu Chaimeeboon1 and Khanista Nameel*, Implementation a WebEx Conferencing Testbed for DLIT Classroom at RMUTP Research Journal

5. Mandy M. Archibald1,2,3, Rachel C. Ambagtsheer2,4, Mavourneen G. Casey4,Michael Lawless2,3 Using Zoom Videoconferencing for Qualitative Data Collection: Perceptions and Experiences of Researchers and at International Journal of Qualitative Methods Volume 18: 1-8

6. Kashyap, S. Sreenath, and Ved Vyas Dwivedi. "Numerical Analysis and Modelling of Microstrip Patch Antennas with Embedded Defective Ground Structure." International Journal of Electrical and Electronics Engineering (IJEEE) 5.4 (2016):9-18

7. Riad, Alaa M., Farahat F. Farahat, and Mahmoud A. Zaher. "Results of Zplag In Arabic E-Learning." International Journal of Computer Science and Engineering (IJCSE) 3.3 (2014):101-108

8. Ghorbani, Maryam., Fateme Noori Sarukolaee, and Madh. Dast-Mard. "The use of participatory learning method in training higher levels of learning in e-learning system." IMPACT: International Journal of Research in Humanities, Arts and Literature (IMPACT: IJRHAL) 2.7 (2014): 1-8.

9. Mudassir Khan, Mohd Ayyoob. "The scope of E-learning in the computer science \& technologies." International Journal of Computer Science Engineering and Information Technology Research (IJCSEITR) 6.6 (2016): 1-6.

10. Fatma, Shaikh Farhat. "E-learning trends issues and challenges." International Journal of Economics, Commerce and Research (IJECR) 3.2 (2013): 1-10.

11. Muzamil, Gazi Tareq. "Application of E-Learning Tools in Teaching English to Undergraduate Students." International Journal of English and Literature (IJEL) 5.3 (2015):41-46

12. Kapur, Meetu Bhatia. "Merging Technology with Language-Enhancement in Learning and Teaching Strategy." International Journal of English and Literature (IJEL) Special Edition (2014):59-68.

13. Karthick, S., et al. "Language through E-Learning." International Journal of English and Literature (IJEL) 3.3 (2013):21-26 